\title{
Relation between weight gain and beta-cell secretory activity and non-esterified fatty acid production in 7-year-old African children: results from the Birth to Ten study
}

\author{
N.J. Crowther ${ }^{1}$, J. Trusler ${ }^{1}$, N. Cameron ${ }^{2}$, M. Toman ${ }^{1}$, I. P. Gray ${ }^{1}$ \\ ${ }^{1}$ Department of Chemical Pathology, South African Institute for Medical Research, University of the Witwatersrand Faculty \\ of Health Sciences, Johannesburg, South Africa \\ ${ }^{2}$ Department of Human Sciences, Loughborough University, Loughborough, Leicestershire, UK
}

\begin{abstract}
Aims/hypothesis. This study aimed to assess the effects of fetal and childhood growth on beta-cell activity and insulin sensitivity in 7-year-old children.

Methods. Insulin, des-31,32 proinsulin, proinsulin, non-esterified fatty acids and glucose concentrations were measured in oral glucose tolerance tests in 152 South African children for whom longitudinal weight data was available.

Results. Children with low weights at birth and 7 years (low-low) had relatively low beta-cell activity whereas children with low birth weight and high weight at 7 years (low-high) had relatively high beta-cell activity. The low-low group had higher 30min glucose concentrations than children with high birth weights. When each insulin-related peptide was expressed as a percentage of all these peptides the low-low children had the highest percentage of insulin but the lowest of the prohormones. The low-high
\end{abstract}

children had the lowest percentage of insulin but the highest of the prohormones. Non-esterified fatty acid concentrations were lowest and their suppression post-glucose load highest in the low-high group. Conclusion/interpretation. Poor fetal and neonatal growth give rise to low beta-cell numbers compensated for by increased efficiency of proinsulin processing to insulin. Poor fetal followed by higher postnatal growth results in low beta-cell numbers and reduced whole-body glucose uptake which leads to reduced efficiency in the processing of proinsulin. Growth in utero and postnatally therefore have profound effects on beta-cell activity and insulin sensitivity with poor fetal coupled with high postnatal growth being detrimental to these processes but not detrimental to the suppression of lipolysis. [Diabetologia (2000) 43: 978-985]

Keywords Thrifty phenotype, fetal and postnatal growth, insulin, proinsulin, NEFA.
The 'thrifty phenotype' hypothesis proposes that fetal under-nutrition leads to fewer beta-cells within the developing pancreas [1]. This may be due either to poor vascularisation or another unknown mechanism whereby the environment defines allometric growth (increase in size of a part of the body related

Received: 14 September 1999 and in revised form: 17 April 2000

Corresponding author: N.J. Crowther, Department of Chemical Pathology, South African Institute for Medical Research, University of the Witwatersrand Faculty of Health Sciences, 7 York Road, Parktown 2193, Johannesburg, South Africa Abbreviations: HOMA: Homeostasis model assessment. to growth of the whole organism). This is not dysfunctional unless the individual changes behaviour entailing increased nutritional intake or is limited to a particular type of nutrition. The transitions in diet during fetal-neonatal-childhood periods i.e. from high carbohydrate, low fat in utero to high fat, low carbohydrate during breast feeding and high carbohydrate, low fat afterwards, perhaps suggests that fat and carbohydrate are not the key dietary factors involved. Rather, absolute kilojoule or protein intake $[2,3]$ or specific intakes or omissions of protein/amino acids are more likely candidates [4]. The dysfunctional nature of the response becomes overt particularly when the phenotype reaches obesity [5]. Under such conditions the reduced beta-cell complement cannot 
consistently cope with the demands and diabetes may occur. Studies have shown that insulin concentrations increase with decreasing birth weight $[6,7]$. Thus poor fetal nutrition may adversely affect not only insulin secretion, but sensitivity as well.

The black population of South Africa has both a high prevalence and incidence of low birth weight children [8,9] and adult obesity [10]. Previous work has shown that birth weight and glucose tolerance have an inverse relationship and that children who gain weight in excess of that predicted by weight percentile curves are less glucose tolerant than those who track within their weight percentile throughout childhood [11].

This study reports the effect of postnatal weight gain on beta-cell activity as expressed by proinsulin and des-31,32 proinsulin secretion as well as insulin sensitivity measured as the postprandial suppression of non-esterified fatty acids (NEFAs) and glucose disposal. The study group were children aged 7 participating in a longitudinal study ("Birth to Ten" study) of the health and development of South African children within the Johannesburg conurbation [12].

\section{Subjects and methods}

Subjects. This study was approved by the University of the Witwatersrand Committee for Research on Human Subjects (Medical) and the parents gave informed consent for their children to participate in the study.

The "Birth to Ten" study group has 4029 participants [12]. A pure longitudinal cohort of black South African children was selected from this group. They had all reached full term gestation and had complete data for birth weight and weight and height at 1 and 5 years of age. We selected 240 subjects (120 boys) at random from the 468 participants who met these criteria. Field workers visited each of these chosen families to provide information about the study and request participation. From the 240 children 152 ( 79 boys), 1 child from each family, agreed to participate. This study sample was greater than that required as a result of power analysis $(n=110, \beta=0.80$, $\alpha=0.05)$.

Oral glucose tolerance test. The children were fasted for 10 to $12 \mathrm{~h}$ before the oral glucose tolerance test (OGTT). They were weighed and their heights measured. An anaesthetic cream was applied to the site of the decubitus vein and $30 \mathrm{~min}$ later a cannula was inserted. A fasting blood sample was taken and $1.75 \mathrm{~g} \cdot \mathrm{kg}^{-1}$ of glucose given to each child orally in the form of Lucozade. Further blood samples were taken 30 and $120 \mathrm{~min}$ after the glucose load. Blood samples were immediately centrifuged and glucose concentrations measured. Serum samples for insulin, proinsulin, des-31,32 proinsulin and NEFA were stored at $-70^{\circ} \mathrm{C}$ until assayed.

Biochemical analyses. Glucose and NEFA concentrations were measured using commercially available enzymatic colourimetric methods (Boehringer Mannheim, Mannheim, Germany). Insulin was measured using an insulin-specific immuno-enzymetric assay (Medgenix, Fleurus, Belgium). The lower limit of sensitivity for the insulin assay was $1.0 \mathrm{pmol} / \mathrm{l}$ and the intraassay and inter-assay coefficients of variations $(\mathrm{CV})$ were 3.0
$5.3 \%$ and 5.6-9.8\%, respectively. Proinsulin and des-31,32 proinsulin were measured using a two-site immunoradiometric assay [13]. The lower limit of detection for both proinsulin and des-31,32 proinsulin was $1.0 \mathrm{pmol} / \mathrm{l}$ and the intra-assay and inter-assay CVs were less than $5 \%$ for both.

Insulin resistance was calculated using the homeostasis model assessment (HOMA) [14] and beta-cell function by both HOMA and calculating the change in insulin and glucose concentrations over the first $30 \mathrm{~min}$ of the OGTT i.e. $\Delta$ Insu$\operatorname{lin}_{30} / \Delta$ Glucose $_{30}(\Delta \mathrm{I} / \Delta \mathrm{G})[15]$.

Anthropometric measurements. Weight at birth and 7 years of age as measured by standard procedures [16] were used in the current analysis. Weight velocity between birth and 7 years was calculated and expressed as $\mathrm{kg} / \mathrm{year}$.

Data presentation and statistical analysis. The children were divided into four groups: those with birth weight and weight at 7 years below the median ( $3.1 \mathrm{~kg}$ for birth weight and $22.5 \mathrm{~kg}$ for weight at 7 years) were designated low-low $(n=49)$; those with birth weight below and weight at 7 years above the median were designated low-high $(n=27)$; those with birth weight and weight at 7 years above the median were designated highhigh $(n=47)$; those with birth weight above and weight at 7 years below the median were designated high-low $(n=29)$.

The total insulin, proinsulin, des-31,32 proinsulin, NEFA and glucose concentrations during the course of the OGTT were calculated by measuring the area under the curve (AUC) using the trapezoid rule. The percentage levels of insulin, des-31,32 proinsulin and proinsulin were calculated by dividing the total concentration (AUC) of each peptide by the sum of the total concentrations of all the peptides and multiplying by a hundred. The percentage suppression of NEFA at 30 and 120 min was calculated thus:

[1 - (NEFA concentration at 30 or $120 \mathrm{~min} /$ Fasting NEFA concentration] $\times 100$

Two-way ANOVA was used to determine the effect of birth weight and weight at 7 years (both split into high-weight and low-weight categories as described above) on HOMA, $\Delta \mathrm{I} /$ $\Delta G$, percentage insulin-related peptides, percentage NEFA suppression levels and the AUC measured concentrations of insulin-related peptides and glucose. One-way ANOVA was used to examine differences between the four groups of children for the variables listed above and for concentrations of insulin-related peptides, glucose, NEFA and percentage NEFA suppression at the 0,30 and 120 min time points of the OGTT. The HOMA, $\Delta \mathrm{I} / \Delta \mathrm{G}$, insulin, proinsulin and des-31,32 proinsulin data were skewed and were therefore logged before analysis. Statistical significance was defined as $p$ less than 0.05 .

\section{Results}

Anthropometric data. The high-high and high-low children had higher $(p<0.001)$ birth weights than both the low-low and low-high groups $(3.5 \pm 0.3$ and $3.4 \pm 0.3 \mathrm{~kg}$ vs $2.7 \pm 0.3$ and $2.8 \pm 0.3 \mathrm{~kg}$ respectively). The low-low $(20.5 \pm 1.5 \mathrm{~kg})$ and high-low $(20.6 \pm 1.6$ $\mathrm{kg}$ ) groups of children weighed significantly less $(p<0.0005)$ than the low-high $(24.4 \pm 1.6 \mathrm{~kg})$ and high-high $(26.3 \pm 6.1 \mathrm{~kg})$ children at 7 years of age. Weight velocity was higher $(p<0.0005)$ in high-high 
Table 1. Concentrations of glucose $(\mathrm{mmol} / \mathrm{l})$, insulin, des31,32 proinsulin and proinsulin (all pmol/l) in 7-year-old children during the course of an oral glucose tolerance test

\begin{tabular}{lcccc}
\hline Measurements & Low-low & Low-high & High-high & High-low \\
\hline Glucose: fasting & $4.2 \pm 0.1$ & $4.3 \pm 0.1$ & $4.1 \pm 0.1$ & $4.1 \pm 0.1$ \\
30 mins & $6.5 \pm 0.2$ & $6.3 \pm 0.2$ & $6.0 \pm 0.1^{\mathrm{a}}$ & $5.8 \pm 0.2^{\mathrm{a}}$ \\
120 mins & $4.4 \pm 0.2$ & $4.5 \pm 0.2$ & $4.4 \pm 0.1$ & $4.0 \pm 0.3$ \\
Insulin: fasting & $46 \pm 5$ & $53 \pm 8$ & $41 \pm 4$ & $46 \pm 5$ \\
30 mins & $252 \pm 17$ & $306 \pm 23$ & $305 \pm 32$ & $255 \pm 26$ \\
120 mins & $94 \pm 10$ & $137 \pm 19^{\mathrm{a}}$ & $123 \pm 15$ & $96 \pm 25$ \\
Des-proinsulin: & & & & \\
fasting & $1.7 \pm 0.3$ & $3.6 \pm 0.7^{\mathrm{b}}$ & $3.1 \pm 0.5^{\mathrm{a}}$ & $2.2 \pm 0.4$ \\
30 mins & $14.8 \pm 1.6$ & $18.0 \pm 2.7$ & $16.4 \pm 2.2$ & $15.8 \pm 2.5$ \\
120 mins & $9.9 \pm 1.4$ & $14.4 \pm 2.7$ & $15.5 \pm 2.7$ & $10.2 \pm 2.9$ \\
Proinsulin: fasting & $3.4 \pm 0.4$ & $3.9 \pm 0.6$ & $2.7 \pm 0.2^{\mathrm{c}}$ & $3.3 \pm 0.4$ \\
30 mins & $8.4 \pm 0.7$ & $11.9 \pm 1.2^{\mathrm{a}}$ & $9.5 \pm 0.9$ & $7.9 \pm 1.0^{\mathrm{c}}$ \\
120 mins & $8.3 \pm 0.9$ & $13.2 \pm 1.5^{\mathrm{b}}$ & $10.0 \pm 0.9$ & $9.7 \pm 1.6$ \\
\hline Comparison & & &
\end{tabular}

Comparison of means by one-way ANOVA: ${ }^{a} p<0.05$ and ${ }^{\mathrm{b}} p<0.005$ vs low-low children; ${ }^{\mathrm{c}} p<0.05$ versus low-high children

$(3.2 \pm 0.8 \mathrm{~kg} /$ year $)$ and low-high $(3.1 \pm 0.3 \mathrm{~kg} /$ year $)$ than low-low $(2.5 \pm 0.2 \mathrm{~kg} / \mathrm{year})$ and high-low $(2.5 \pm 0.2 \mathrm{~kg} /$ year $)$ children.

Insulin, des-31,32 proinsulin, proinsulin and glucose concentrations. The $120 \mathrm{~min}$ insulin concentration of the low-high children was significantly higher than that of the low-low children (Table 1) as was the total insulin concentration (Fig. 1).

The fasting des-31,32 proinsulin concentration of the low-low children was significantly lower than that of the high-high and low-high children (Table 1). The total des-31,32 proinsulin concentration was lowest in the low-low group significantly so compared to the low-high and the high-high children (Fig. 1).

The proinsulin concentrations for the low-high children were significantly higher than: the high-high children at fasting; the low-low children at 30 and $120 \mathrm{~min}$; the high-low children at $30 \mathrm{~min}$ (Table 1). The total proinsulin concentrations for the low-high children were significantly higher than those of the low-low, high-low and high-high children (Fig. 1).

Two-way ANOVA showed that for total concentrations of insulin, proinsulin and des-31,32 proinsulin weight at 7 years had an influence on all three peptides $(F=5.82, \quad p=0.018 ; \quad F=6.56, \quad p=0.012$; $F=14.10, p<0.0005$, respectively).

The 30-min glucose concentration was highest in the low-low group and significantly higher than the high-high and high-low children (Table 1). Total glucose concentration (area under the curve) was highest in the low-low children and was significantly higher than in the high-low children (Fig.1). Twoway ANOVA showed that birth weight had an effect on total glucose concentrations $(F=4.69, p=0.033)$ and that interaction between birth weight and
Table 2. Measurement by HOMA of insulin resistance and assessment of beta-cell function using the changes in insulin and glucose concentrations between 0 and $30 \mathrm{~min}$ of an oral glucose tolerance test

\begin{tabular}{lcccc}
\hline Measurements & Low-low & Low-high & High-high & High-low \\
\hline $\begin{array}{l}\text { HOMA mea- } \\
\text { surement of insu- } \\
\text { lin resistance }\end{array}$ & $1.27 \pm 0.18$ & $1.55 \pm 0.30$ & $1.09 \pm 0.11$ & $1.15 \pm 0.14$ \\
& & & & \\
$\begin{array}{l}\text { Beta-cell func- } \\
\text { tion }\left(\Delta \text { Insulin }_{30} /\right.\end{array}$ & $108 \pm 13$ & $175 \pm 29^{\mathrm{a}}$ & $153 \pm 21$ & $152 \pm 21$ \\
$\Delta$ Glucose $\left._{30}\right)$ & $108 \pm$
\end{tabular}

Comparison of means by one-way ANOVA: ${ }^{a} p<0.05$ vs lowlow group

weight at 7 years just missed significance $(F=3.32$, $p=0.07)$.

HOMA and beta-cell function analyses. Insulin resistance and beta-cell function $(\Delta \mathrm{I} / \Delta \mathrm{G})$ were highest in the low-high children, the latter variable being significantly higher than in the low-low children (Table 2). Two-way ANOVA showed that weight at 7 years had a strong but not significant influence on $\Delta \mathrm{I} / \Delta \mathrm{G}$ $(F=3.75, p=0.055)$ and that there was a significant interaction between birth weight and weight at 7 years $(F=4.32, p=0.04)$. There were no significant differences between the groups for levels of beta-cell function as calculated by HOMA (low-low $261 \pm 47$; low-high $221 \pm 63$; high-high $283 \pm 47$; high-low $224 \pm 38)$.

Percentage levels of insulin and related prohormones. The percentage level of insulin was lowest in the lowhigh group of children and was significantly so compared to the low-low and high-high children. The low-low group had significantly higher percentage insulin compared with the high-high children (Fig. 1).

The percentage of des-31,32 proinsulin was lowest in the low-low children being significantly so compared to the low-high and high-high children (Fig. 1).

The percentage level of proinsulin was highest in the low-high children being significantly so compared with the high-high group (Fig. 1).

Two-way ANOVA showed that the percentage levels of insulin and des-31,32 proinsulin were influenced by weight at 7 years $(F=10.83, p=0.0015$; $F=13.96, p<0.0005$, respectively) and that for the percentage insulin levels there was an interaction between birth weight and weight at 7 years $(F=5.59$, $p=0.021)$. Interactions between birth weight and weight at 7 years were just less than significant for percentage levels of proinsulin $(F=2.88, p=0.094)$ and des-31,32 proinsulin $(F=3.43, p=0.068)$.

NEFA concentrations. The plasma NEFA concentrations were lowest in the low-high children (Ta- 


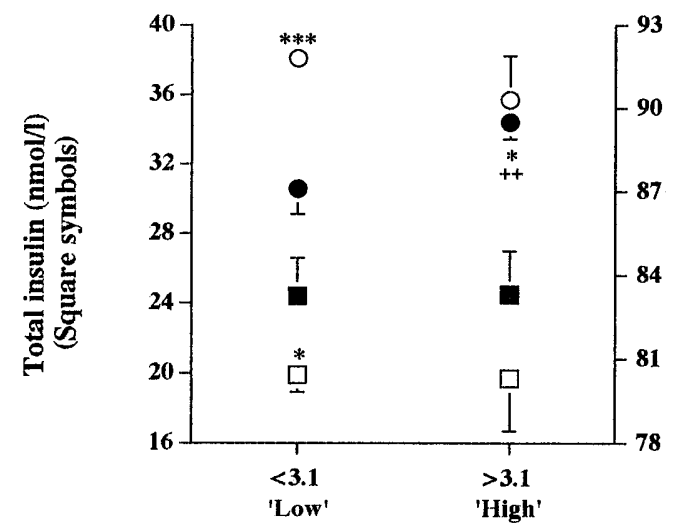

A
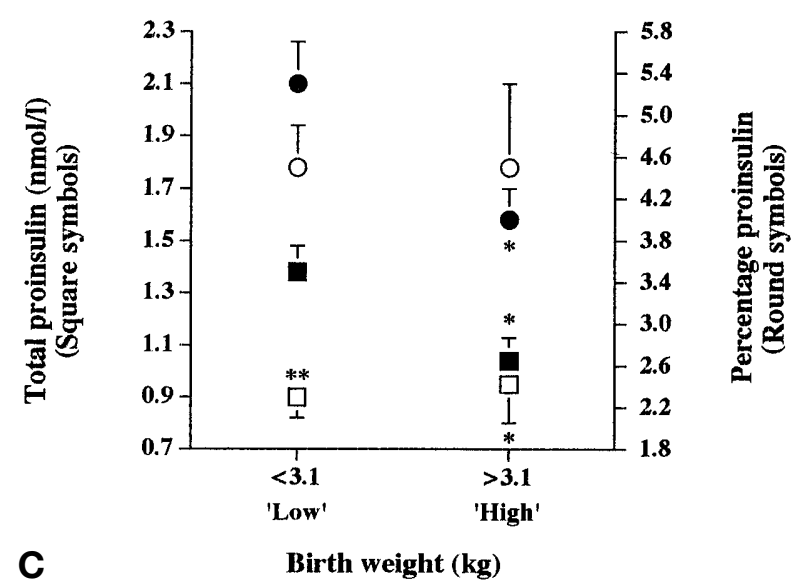

Fig. 1 A-D. Total (area under the curve) and percentage levels of $\mathbf{A}$ insulin, $\mathbf{B}$ des-31,32 proinsulin, $\mathbf{C}$ proinsulin, $\mathbf{D}$ glucose (total concentrations only) in 7-year-old children (see 'Data Presentation' section of 'Materials and Methods' for details of how calculation of percentage levels was carried out). $\square, 0$ Total and percentage levels, respectively, in children with weight at 7 years below $22.5 \mathrm{~kg}$ ('low'); $\mathbf{\square}$, Total and percentage levels, respectively in children with weight at 7 years above $22.5 \mathrm{~kg}$ ('high'). $* p<0.05, \quad * * p<0.005$ and $* * * p<0.0005$ vs children with 'low' birth weight and 'high' weight at 7 years (i.e. low-high group) $+p<0.05$ and $++p<0.005$ vs children with 'low' weight at birth and 7 years (i. e. low-low group)

ble 3). This group also had the greatest suppression of NEFA concentrations at the $30 \mathrm{~min}$ time point of the OGTT being statistically significantly different from that of the high-high and low-low groups of children. There were no significant differences between the 120 min NEFA suppression concentrations. Two-way ANOVA showed that with respect to percentage suppression of NEFA concentrations at $30 \mathrm{~min}$, there was an interaction between birth weight and weight at 7 years $(F=4.57$, $p=0.035)$.
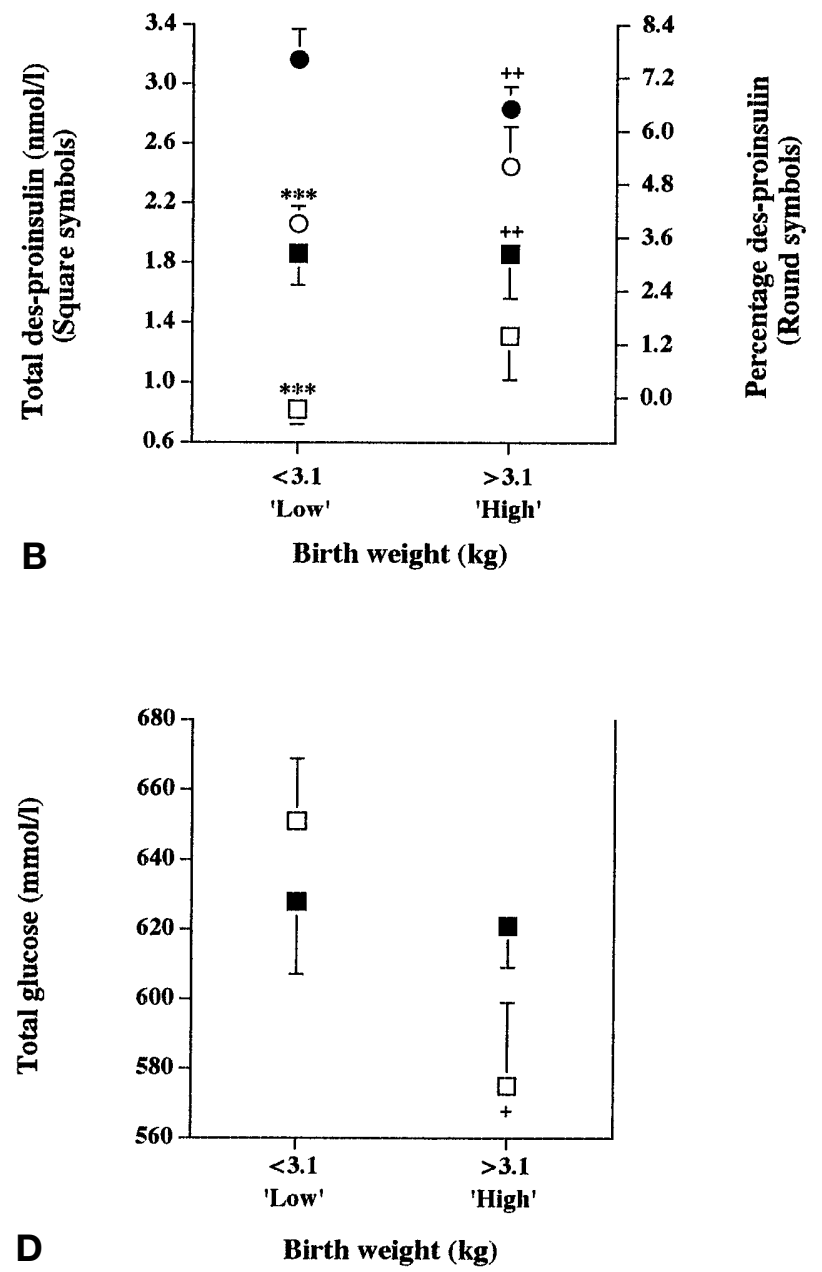

Correlations. A negative correlation was observed between fasting concentrations of NEFA and those of insulin concentrations $(r=-0.27, p=0.005$, $n=115)$ and between 120-min NEFA concentrations and 120-min insulin concentrations $(r=-0.38$, $p<0.0005, n=95$ ) after correcting for age and weight in a multiple linear regression analysis. The 30-min concentration of glucose (used as the dependent variable) correlated with that of NEFA concentration $(r=0.21, p=0.04, n=99)$ independently of age, weight and that of insulin concentration.

\section{Discussion}

Our study shows that maintaining a low weight at birth and 7 years (possibly due to poor fetal and neonatal nutrition) could lead to low beta-cell numbers and activity and poor glucose tolerance. Thus, the low-low children have relatively limited beta-cell activity, high glucose concentrations and the lowest $\Delta \mathrm{I} /$ $\Delta G$ levels. Furthermore, in humans low birth weight is associated with low beta-cell mass [17] and in rats fed a low protein diet during pregnancy neonates are born with reduced beta-cell numbers [2, 3]. Insulin, expressed as a proportion of all the insulin-related 
Table 3. NEFA concentrations $(\mu \mathrm{mol} / \mathrm{l})$ and percentage suppression of NEFA during the course of an oral glucose tolerance test in 7-year-old children (see 'Data Presentation' section of 'Materials and methods' for details of how calculation of percentage suppression of NEFA was carried out)

\begin{tabular}{ccccc}
\hline $\begin{array}{l}\text { Time } \\
\text { (minutes) }\end{array}$ & Low-low & Low-high & High-high & High-low \\
\hline 0 NEFA & $774 \pm 76$ & $768 \pm 83$ & $741 \pm 64$ & $813 \pm 108$ \\
30 NEFA & $382 \pm 48$ & $297 \pm 43$ & $404 \pm 50$ & $387 \pm 80$ \\
& $\left(46 \pm 4^{\mathrm{a}}\right)$ & $(59 \pm 4)$ & $\left(45 \pm 4^{\mathrm{a}}\right)$ & $(52 \pm 6)$ \\
120 NEFA & $85 \pm 14$ & $73 \pm 22$ & $66 \pm 16$ & $53 \pm 13$ \\
& $(84 \pm 3)$ & $(87 \pm 4)$ & $(89 \pm 4)$ & $(86 \pm 4)$ \\
\hline
\end{tabular}

Figures in parentheses are percentage levels. Comparison of means by one-way ANOVA: ${ }^{a} p<0.05$ vs low-high children

peptides, was highest in the low-low children whereas the proportions of proinsulin and des-31,32 proinsulin as well as absolute levels were low. This suggests that processing is more complete than in other groups of children and could be a compensatory response to reduced beta-cell numbers. Despite the more effective conversion of proinsulin to insulin these children have low insulin concentrations which we suggest reflects low beta-cell mass.

Low birthweight subjects who progressed to high weight at 7 years had the greatest beta-cell response and HOMA-assessed insulin resistance levels but poor glucose tolerance. Low birth weight $[6,7]$ and increased adipose mass [18] can both give rise to insulin resistance; a previous study has shown that lowhigh children have high indices of obesity [11]. These children also had proportionately the most proinsulin and des-31,32 proinsulin and the least insulin but absolute concentrations of all three were higher than the other groups. This suggests less efficient processing of proinsulin compared with the low-low children but a great enough flux through the processing pathway to increase serum insulin concentrations above the low-low group. The low-high children could also have more beta cells compared with the low-low cohort resulting from higher postnatal nutrition. Reduced beta-cell mass relative to the high birthweight groups, together with increased insulin resistance could explain the poor proinsulin-processing efficiency in the low-high subjects. High serum concentrations of proinsulin and des-31,32 proinsulin have been observed in Type II diabetic patients [19, 20], glucose intolerant subjects [21] and have been used as indictors of people at risk of developing Type II diabetes [22].

Higher weight at birth could increase beta-cell numbers and therefore function with a related improvement in glucose tolerance, as shown by the lower glucose concentrations of the high than the low birthweight children. The high-high and high-low groups of children have intermediate proportions of insulin-related peptides compared with the two low birthweight groups. Intuitively, higher birth weights could reflect better fetal nutrition which leads to better beta-cell development and lower insulin resistance.

The 'thrifty phenotype' hypothesis states that poor fetal growth leads to reduced beta-cell mass or function or both [1]. This is supported by the low betacell secretory response of the low-low children. Beta-cell dysfunction is also apparent in the low-high children who have high plasma and percentage levels of des-31,32 and intact proinsulin and low percentage levels of insulin. Compared with the low-low the low-high subjects have, however, higher plasma insulin and $\Delta \mathrm{I} / \Delta \mathrm{G}$ levels possibly as a result of higher postnatal nutrition in the latter subjects leading to a higher beta-cell mass. Thus, high weight gain in childhood could allow for increased beta-cell neogenesis but also be detrimental to beta-cell function especially when it occurs in low birthweight children. This is shown by the low-high children having higher fasting, total and percentage levels of proinsulin and lower percentage insulin levels but similar weight velocities compared with the high-high children. This interaction between birth weight and weight at 7 years is highlighted by two-way ANOVA which shows that it influences beta-cell function $(\Delta \mathrm{I} / \Delta \mathrm{G})$, percentage levels of insulin and postprandial suppression of NEFA concentrations. An earlier study using the same group of children [11] found that total insulin concentrations correlated negatively with birth weight but only after adjustment for current weight. This suggests that weight gain between birth and 7 years is a major determinant of insulin concentrations [23]. Two-way ANOVA shows that high weight at 7 years is associated with increased insulin and prohormone concentrations and high percentage des31,32 proinsulin levels indicating that high weight at 7 years independent of birth weight can also influence beta-cell activity.

Additional support for the 'thrifty phenotype' hypothesis comes from the association of low birthweight with high glucose concentrations in this study and from a previous study showing a negative correlation between birth weight and glucose concentrations in this same cohort of children from the "Birth to Ten" study group [11].

The low-low children show characteristics of reduced beta-cell mass whereas the low-high group have beta-cell dysfunction arising from both insulin resistance and possible reduction in beta-cell numbers. The low-high children could therefore be at risk of developing Type II diabetes later in life especially if they maintain a high body weight. The lowlow children will be at high risk of developing diabetes if they become obese; studies have shown that low birth weight in conjunction with a high adult BMI predisposes to the development of Type II diabetes [5, 24]. It is also possible that if fetal and postna- 
tal nutrition were very poor these subjects could become diabetic even without becoming obese. Of note is that lean Type II diabetic patients have reduced beta-cell secretory activity compared with obese diabetic patients [25].

Low birth weight is associated with insulin resistance in adults $[6,7]$ but not with poor beta-cell function. In our investigation when the low birthweight children were, however, examined as low-low and low-high groups an association between low birth weight and poor beta-cell function was seen. The reasons for our new findings could be that other studies have not used this approach to evaluate indices of beta-cell activity and most have studied the relation between birthweight and glucose tolerance in adult, First World populations; our study used infants from a developing country in which increased urbanisation is causing a nutritional transition to a more westernised diet [26]. Two studies that measured glucose tolerance in children from a developing country (India) also found low birth weight to be associated with poor glucose tolerance $[27,28]$.

The absolute concentrations of circulating insulinrelated peptides are dependent not only on beta-cell secretion but also the clearance rate of these peptides. Insulin clearance has been shown to be reduced in obese compared with non-obese children [29]. A difference in clearance rates is, however an unlikely single cause of the variation in serum insulin concentrations as this would not explain the inter-group differences in the proportions of insulin-related peptides. The similar rates of decline of insulin concentrations observed after $30 \mathrm{~min}$ in this study and the differences in absolute and percentage levels of insulin and the prohormones are better explained in theory by variation in secretion rather than clearance rates.

We used HOMA to assess insulin resistance; betacell function was assessed using HOMA and the 30min increment in insulin levels $(\Delta \mathrm{I} / \Delta \mathrm{G})$ and other studies have shown that $\Delta \mathrm{I} / \Delta \mathrm{G}$ is the better measurement of beta-cell function $[30,31]$. The HOMA method for calculating insulin resistance and $\Delta \mathrm{I} / \Delta \mathrm{G}$ gave credible results in both this and a previous study (HOMA only) [11]: both have been tested in a variety of different population groups [15, 27, 30, 31]. A recent investigation has also used both these models for assessing glucose tolerance in 8-year-old Indian subjects [27]. Although neither method has been validated in children we believe that they are the best currently available techniques for measuring insulin resistance and beta-cell function in a large group of children.

Postprandial suppression of NEFA levels is mainly due to the antilipolytic action of insulin [32] thus the negative correlation between NEFA and insulin in this study. During the course of the OGTT suppression of NEFA levels was greatest in the low-high chil- dren. This is notable because data on glucose clearance showed that low-high children were more insulin resistant than other groups. Possible mechanisms by which this can occur include differential tissue expression of the insulin receptor or tissue-specific down-regulation of the insulin receptor signalling pathways. Selective resistance of different metabolic functions to the action of insulin has been observed before: in essential hypertension insulin-stimulated glucose uptake is reduced but suppression of lipolysis is not [33].

The low-high and high-high children have similar insulin concentrations but the former group suppress NEFA concentrations more effectively. This could be a metabolic adaptation induced by a low nutrient fetal environment and ensures storage of triglycerides in times of high nutrient intake. The high-high children might have been exposed to a nutrient-rich environment during fetal and postnatal periods and therefore their metabolism has adapted to reduce stored triglyceride concentrations. The low-low children have reduced insulin concentrations which could act in their favour by causing immediate release, rather than storage of NEFA for use by essential organs such as the CNS. Furthermore, by maintaining high serum NEFA concentrations, the Randle cycle [34] could reduce glucose uptake in insulin-sensitive tissues ensuring preferential use of glucose by essential tissues. Our results show that NEFA concentrations correlate positively with postprandial glucose concentrations. In the high-low children insulin suppresses NEFA to a level intermediate to that of the low-high group and the high-high, low-low groups.

Studies carried out on the offspring of rats fed a low protein diet during pregnancy followed by a postweaning diet higher in protein have shown that adipocytes isolated from these animals have higher insulinreceptor numbers [35] and increased phosphatidylinositol 3-kinase activity associated with insulin receptors [36] than adipocytes from the offspring of rats fed a diet containing high protein during pregnancy. Thus, adipocyte insulin sensitivity can be modified by the protein content of the diet during pregnancy. If a similar mechanism exists in humans then this could explain the higher insulin sensitivity of NEFA suppression observed in the low-high children.

The reasons for low weight at birth and 7 years and changes in weight tracking that have been shown in this study, are not known. The most obvious cause is nutritional but we cannot rule out other factors such as maternal smoking and alcohol intake. The 'thrifty phenotype' hypothesis [1] puts much emphasis on nutrition during fetal life influencing beta-cell numbers and insulin sensitivity and data from experimental animal studies supports this $[2,3,37]$. Our study shows that in humans, factors acting between birth and 7 years of age in combination with factors in utero 
are important in determining the adequacy of betacell function. The factors involved are not known but nutrition must be important. Another study has shown that $50 \%$ of the adult complement of islets are present within the pancreas by the age of 1 year [38] and therefore it is feasible that nutritional intake during both fetal and postnatal periods has implications for beta-cell numbers and insulin sensitivity.

Glucose intolerance could result from a reduced capacity of the endocrine pancreas to process proinsulin into insulin. This could arise due to a combination of poor fetal nutrition which reduces beta-cell numbers and increases insulin resistance, and high postnatal caloric intake. The insulin secretory and proinsulin-processing capacity of the islet beta-cells could then be overwhelmed. Furthermore, exposure to such extremes of nutritional intake leads to metabolic adaptations that involve differential responses to insulin action; glucose uptake is reduced while inhibition of lipolysis is enhanced. This ensures that energy stores are maintained for use in times of poor nutrition. We believe that both fetal and postnatal nutrition have strong influences on beta-cell growth and that in developing countries poor nutrition at these times will profoundly affect glucose tolerance. The rising incidence of obesity within these countries especially in children [39] will lead to further rises in Type II diabetes prevalence which can be avoided by ensuring adequate nutrition during both pregnancy and early childhood.

Acknowledgements. We would like to thank the Chemical Pathology routine laboratory at Chris Hani-Baragwanath Hospital for doing the glucose assays, Sister N Ramela for taking the blood samples and the Birth to Ten research assistants and study participants who made this project possible. We would also like to thank Johnson + Johnson and SmithKline and Beecham for their donations. The Birth to Ten study receives financial and logistic support from: the Urbanisation and Health Programme of the Medical Research Council; the Anglo-American and DeBeers Chairman's Fund Educational Trust; the Centre for Science Development of the Human Sciences Research Council; the University of the Witwatersrand; Kentucky Fried Chicken; Liberty Life; Liqui-Fruit; Delmas Milling; Astra Pharmaceuticals and Suzuki. N. J. Crowther, receives research funding from the South African Institute for Medical Research and from the South African Medical Research Council.

\section{References}

1. Hales CN, Barker DJ (1992) Type II (non-insulin-dependent) diabetes mellitus: the thrifty phenotype hypothesis. Diabetologia 35: 595-601

2. Snoeck A, Remacle C, Reusens B, Hoet JJ (1990) Effect of a low protein diet during pregnancy on the fetal rat endocrine pancreas. Biol Neonate 57: 107-118

3. Garofano A, Czernichow P, Bréant B (1997) In utero undernutrition impairs rat beta-cell development. Diabetologia 40: 1231-1234
4. Cherif H, Reusens B, Ahn MT, Hoet JJ, Remacle C (1998) Effects of taurine on the insulin secretion of rat fetal islets from dams fed a low-protein diet. J Endocrinol 159: 341-348

5. Hales CN, Barker DJ, Clark PM et al. (1991) Fetal and infant growth and impaired glucose tolerance at age 64 . BMJ 303: 1019-1022

6. Phillips DI, Barker DJ, Hales CN, Hirst S, Osmond C (1994) Thinness at birth and insulin resistance in adult life. Diabetologia 37: 150-154

7. Leger J, Levy-Marchal C, Bloch J et al. (1997) Reduced final height and indications for insulin resistance in 20 year olds born small for gestational age: regional cohort study. BMJ 315: 341-347

8. Stein H, Ellis U (1974) The low birth weight African baby. Arch Dis Child 49: 156-159

9. Cooper PA, Simchowitz ID, Sandler DL, Rothberg AD, Davies VA, Wainer S (1996) Prevalence of hyaline membrane disease in black and white low-birth-weight infants. S Afr Med J 84: 23-25

10. Steyn K, Jooste PL, Bourne L et al. (1991) Risk factors for coronary heart disease in the black population of the Cape Peninsula. The BRISK Study. S Afr Med J 79: 480-485

11. Crowther NJ, Cameron N, Trusler J, Gray IP (1998) Association between poor glucose tolerance and rapid post natal weight gain in seven-year-old children.Diabetologia 41: $1163-1167$

12. Richter L, Yach D, Cameron N (1995) Enrolment into Birth to Ten (BTT): population and sample characteristics. Paediatric Perinatal Epidemiol 9: 109-120

13. Sobey WJ, Beer SF, Carrington CA et al. (1989) Sensitive and specific two-site immunoradiometric assays for human insulin, proinsulin, 65-66 split proinsulin and 32-33 split proinsulins. Biochem J 260: 535-541

14. Matthews DR, Hosker JP, Rudenski AS, Naylor BA, Treacher DF, Turner RC (1985) Homeostasis model assessment: insulin resistance and b-cell function from fasting plasma glucose and insulin concentrations in man. Diabetologia 28: 412-419

15. Kosaka K, Hagura R, Kuzuya T (1977) Insulin responses in equivocal and definite diabetes with special reference to subjects who had mild glucose intolerance but later developed definite diabetes. Diabetes 26: 944-952

16. Cameron N (1984) The measurement of human growth. Croom-Helm, London

17. Van Assche FA, Aerts L (1979) The fetal endocrine pancreas. Contrib Gynecol Obstet 5: 44-57

18. Walker M (1995) Obesity, insulin resistance, and its link to non-insulin-dependent diabetes mellitus. Metabolism 44 [Suppl 3]: 18-20

19. Mako ME, Starr J, Rubinstein AH (1977) Circulating proinsulin in patients with maturity onset diabetes. Am J Med 63: 865-869

20. Temple RC, Carrington CA, Luzio SD et al. (1989) Insulin deficiency in non-insulin-dependent diabetes. Lancet i: 293-295

21. Davies MJ, Rayman G, Gray IP, Day JL, Hales CN (1993) Insulin deficiency and increased plasma concentrations of intact and 32/33 split proinsulin in subjects with impaired glucose tolerance. Diabet Med 10: 313-320

22. Nijpels G, Popp-Snijders C, Kostene PJ, Bouter LM, Heine RJ (1996) Fasting proinsulin and 2 hour post glucose concentrations predict the conversion to NIDDM in subjects with impaired glucose tolerance: the Hoorn Study. Diabetologia 39: 113-118

23. Lucas A, Fewtrell MS, Cole TJ (1999) Fetal origins of adult disease - the hypothesis revisited. BMJ 319: 245-249 
24. Valdez R, Athens MA, Thompson GH, Bradshaw BS, Stern MP (1994) Birth weight and adult health outcomes in a biethnic population in the USA. Diabetologia 37: 624-631

25. Arner P, Pollare T, Lithell H (1991) Different aetiologies of Type II (non-insulin-dependent) diabetes mellitus in obese and non-obese subjects. Diabetologia 34: 483-487

26. Rossi-Espagnet A, Goldstein GB, Tabibzadah I (1991) Urbanization and health in developing countries: a challenge for health for all. World Health Stat 44: 185-244

27. Bavdekar A, Yajnik CS, Fall CH et al. (1999) Insulin resistance syndrome in 8-year-old Indian children. Diabetes 48 : 2422-2429

28. Yajnik CS, Fall CH, Vaidya U et al. (1995) Fetal growth and glucose and insulin metabolism in four-year-old Indian children. Diabet Med 12: 330-336

29. Escobar O, Mizuma H, Southern MS et al. (1999) Hepatic insulin clearance increases after weight loss in obese children and adolescents. Am J Med Sci 317: 282-286

30. Phillips DI, Clark PM, Hales CN, Osmond C (1994) Understanding oral glucose tolerance: comparison of glucose or insulin measurements during oral glucose tolerance test with specific measurements of insulin resistance and insulin secretion. Diabet Med 11: 286-292

31. Haffner SM, Miettinen H, Stern MP (1997) The homeostasis model in the San Antonio study. Diabetes Care 20: 1087-1092

32. Karlsson A-K, Attval S, Jansson PA, Sullivan L, Lönnroth P (1995) Influence of the sympathetic nervous system on insulin sensitivity and adipose tissue metabolism: a study in spinal cord-injured subjects. Metabolism 44: 52-58

33. Ferrannini E, Haffner SM, Stern MP (1990) Essential hypertension: an insulin-resistant state. J Cardiovasc Pharmacol 15 [Suppl 5]: S18-S25

34. Randle PJ, Garland PB, Hales CN, Newsholme EA (1963) The glucose-fatty acid cycle. Its role in insulin sensitivity and the metabolic disturbances of diabetes mellitus. Lancet i: 785-789

35. Shepherd PR, Crowther NJ, Desai M, Hales CN, Ozanne SE (1997) Altered adipocyte properties in the offspring of protein malnourished rats. Br J Nutr 78: 121-129

36. Ozanne SE, Nave BT, Wang CL, Shepherd PR, Prins J, Smith GD (1997) Poor fetal nutrition causes long-term changes in expression of insulin signaling components in adipocytes. Am J Physiol 273: E46-E51

37. Hales CN, Desai M, Ozanne SE, Crowther NJ (1996) Fishing in the stream of diabetes: from measuring insulin to the control of fetal organogenesis. Biochem Soc Trans 24: 341-350

38. Rahier J, Wallon J, Henquin J-C (1981) Cell populations in the endocrine pancreas of human neonates and infants. Diabetologia 20: 540-546

39. Popkin BM, Richards MK, Montiero CA (1996) Stunting is associated with overweight in children of four nations that are undergoing the nutrition transition. J Nutr 126: 3009-3016 